\title{
CORRIGENDUM
}

\section{Optimal genotype determination in highly multiplexed SNP data}

Martin Moorhead, Paul Hardenbol, Farooq Siddiqui, Matthew Falkowski, Carsten Bruckner, James Ireland, Hywel B Jones, Maneesh Jain, Thomas D Willis and Malek Faham

European Journal of Human Genetics (2006) 14, 976. doi:10.1038/sj.ejhg.5201655

Correction to: European Journal of Human Genetics (2006), 14, 207-215. doi: 10.1038/sj.ejhg.5201528

Since publication of the above paper, the authors have identified an error in one of the equations. In the following equation, published on $\mathrm{p} 208$ :

$y=\left(2 S_{2} / S_{\text {sum }}\right)^{-1}$

the -1 should not be superscript, so the correct equation reads

$$
y=\left(2 S_{2} / S_{\text {sum }}\right)-1 \text {. }
$$

